\title{
The stability of soil organic carbon across topographies in a tropical rainforest
}

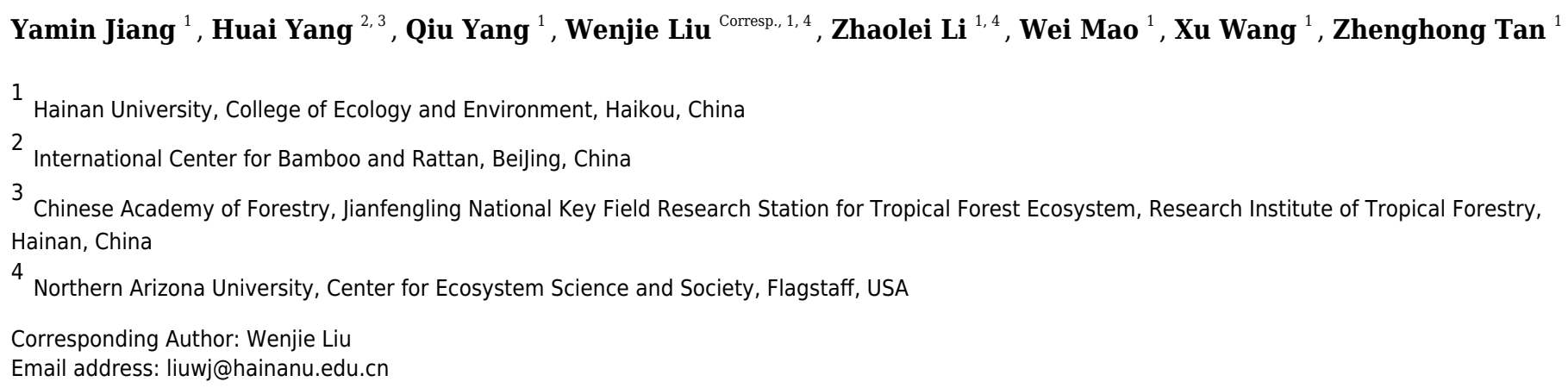

Mechanisms of soil organic carbon (SOC) stability are still unclear in forest ecosystems. In order to unveil the influences of topography on the SOC stability, a 60 ha dynamic plot of a tropical montane rainforest was selected in Jianfengling, in Hainan Island, China and soil was sampled from 60 quadrats. The chemical fractions of the SOC were detected with $13 \mathrm{C}$ CPMAS/NMR and path analyses to explore the mechanisms of SOC stability in different topographies. The chemical fractions of the SOC comprised alkyl carbon $>0$-alkyl carbon $>$ carboxyl carbon > aromatic carbon. The decomposition index (DI) values were greater than 1 in the different topographies, with an average DI value was 1.29, which indicated that the SOC in the study area was stable. Flat and top areas (together named RF) had more favorable nutrients and silt contents compared with steep and slight steep areas (together named RS). The influencing factors of SOC stability varied across the topographies, where SOC, soil moisture (SM) and ammoniacal nitrogen $\left(\mathrm{NH}_{4}{ }^{+} \mathrm{N}, \mathrm{AN}\right)$ were the main influencing factors in the RF, while SM and AN were the main factors in the RS. Greater SOC and AN strengthened the SOC stability, while higher soil moisture lowered SOC stability. The inertia index was higher in the RS than the RF areas, indicating that local topography significantly affects SOC content and SOC stability by changing soil environmental factors. Topography cannot be neglected in considering SOC stability and future $\mathrm{C}$ budgets. 


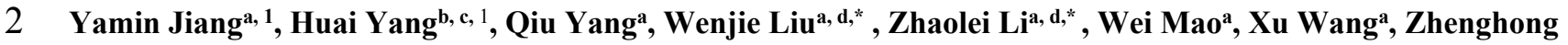
3 Tana $^{\mathrm{a}}$

$4 \quad{ }^{a}$ College of Ecology and Environment, Hainan University, Haikou 570228, China;

5 ' International Center for Bamboo and Rattan, Beijing100102, China;

6 c Jianfengling National Key Field Research Station for Tropical Forest Ecosystem, Research Institute of Tropical

7 Forestry, Chinese Academy of Forestry, Ledong 510520, China;

$8 \quad{ }^{\mathrm{d}}$ Center for Ecosystem Science and Society, Northern Arizona University, Flagstaff, AZ 86011, USA

91 The two authors contributed equally.

*Corresponding author. E-mail address: liuwj@hainanu.edu.cn and zhaoleilee@sdau.edu.cn. 
11 Abstract: Mechanisms of soil organic carbon (SOC) stability are still unclear in forest ecosystems. In order to unveil the influences of topography on the SOC stability, a 60ha dynamic plot of a tropical montane rainforest was selected in Jianfengling, in Hainan Island, China and soil was sampled from 60 quadrats. The chemical fractions of the SOC were detected with 13C CPMAS/NMR and path analyses to explore the mechanisms of SOC stability in different topographies. The chemical fractions of the SOC comprised alkyl carbon $>$ O-alkyl carbon $>$ carboxyl carbon $>$ aromatic carbon. The decomposition index (DI) values were greater than 1 in the different topographies, with an average DI value was 1.29, which indicated that the SOC in the study area was stable. Flat and top areas (together named RF) had more favorable nutrients and silt contents compared with steep and slight steep areas (together named RS). The influencing factors of SOC stability varied across the topographies, where SOC, soil moisture (SM) and ammoniacal nitrogen $\left(\mathrm{NH}_{4}{ }^{+}-\mathrm{N}, \mathrm{AN}\right)$ were the main influencing factors in the RF, while SM and AN were the main factors in the RS. Greater SOC and AN strengthened the SOC stability, while higher soil moisture lowered SOC stability. The inertia index was higher in the RS than the RF areas, indicating that local topography significantly affects SOC content and SOC stability by changing soil environmental factors. Topography cannot be neglected in considering SOC stability and future $\mathrm{C}$ budgets.

Keywords: soil organic carbon stability; topography; tropical forest; 13C CPMAS/NMR; path analysis

\section{Introduction}

The soil organic carbon (SOC) of forests plays an important role in the global carbon cycle (Pan et al. 2011). Changes in SOC storage can significantly impact the global carbon cycle and climate change (Stockmann et al. 2013). SOC stability is the ability of soil organic matter to resist disturbance and maintain its original carbon levels under the present conditions (Wiesmeier et al. 2014). High SOC stability would be beneficial for the accumulation of SOC (Schmidt et al. 2011). The SOC stabilisation mechanisms that are commonly accepted include chemical stabilisation, physical stabilisation, and biochemical stabilisation (Christensen 1996; Fontaine et al. 2007; Six et al. 2002). In terms of chemical stabilisation, SOC consists of chemical fractions of different stability and this has long been considered as the principal mechanism of SOC stability (Yang et al. 2020). The relationship between soil structure and the ability of soil to stabilize soil organic matter indicating that physical protection is a key element in SOC stability (J. Six 2002). Studies on the protection of soil $\mathrm{C}$ by soil texture, such as silt and clay had long been well established (Hassink 1997). Solid 13CNMR technology is a method for dissecting SOC chemical fractions and has been applied into tropical forest soil stability research (Chen 2012; Shang et al. 2013; Wang 2010). Previous studies illustrated that the composition of the SOC chemical fractions is affected by soil microorganisms, soil properties, and carbon input (ElberlingBreuning-Madsen \& Knicker 2013; González-Pérez et al. 2008; Ktigel-Knabner 1997; LorenzLal \& Jiménez 2010). Topographic factors, such as elevation, slope, concavity and convexity, affect water flow and erosion, plants growth and litter decomposition, and hence influence SOC content and quality (Fernández-RomeroLozanoGarcía \& Parras-Alcántara 2014; SunZhu \& Guo 2015). As such, there is inherent heterogeneity in SOC stability associated with the spatial variability of topographic factors. However, studies on factors influencing SOC stability have mainly focused on tree species, soil minerals protection or altitude (Angst et al. 2018) rather than topography. 
Topography itself is a comprehensive factor, thus, it should be taken into consideration in SOC stability. Topography governs the allocation of water and heat resources, which affects the spatial allocation of vegetation and may thus affect the quantity and quality of SOC(SunZhu \& Guo 2015). In addition, the movement of water and nutrients due to different topography types contributes to soil properties heterogeneity (TsuiChen \& Hsieh 2004). Studies found SOC fractions and stability varied across topography. Some studies found in lowland and plain areas alkyl carbon accounted for the most of the SOC fractions and indicated disturbance of soil and soil particle size be the key influencing factors (ChenXu \& Mathers 2004; Shang et al. 2013). However, other studies in plain and hills found a relative lower DI index (all less than 0.9) and attributed the factors to the input of SOC and soil moisture (LorenzLal \& Jiménez 2010; Wang 2010). Studies in plateau found SOC that were not trapped in the iron nodules had a relative higher DI index (1.25) (ElberlingBreuning-Madsen \& Knicker 2013). We hypothesised that nutrients and soil environment factors would be the key influencing factors on SOC stability.

The Jianfengling montane rainforest is one of the best preserved tropical primaeval forests in China ( $\mathrm{Li}$ et al. 2012). Previous studies have found that terrain heterogeneity in this area had a strong effect on the soil properties (Shi 2012) and pointed out that SOC stability is significantly influenced by soil properties(Liu et al. 2007). Soil properties in different topographic positions also have distinctive characteristics under micro-climate conditions (Zhu et al. 2014), which fundamentally influences nutrients, hydrological processes, and thereby, the SOC stability across these topographies. However, there has been a systematic lack of studies specifically addressing how topographies influence the SOC stability by changing soil properties. The objectives of this study were to investigate the differences in soil properties and SOC stability at four topographic positions, and to identify the mechanisms of SOC stability in different topographies in tropical rainforests. To address these objectives, we collected soils from 60 quadrats in a 60ha dynamic plot in different topographical areas in the Jiangenling tropical montane rainforest. The stability of the SOC was demonstrated by SOC chemical fractions which were analysed by 13C-NMR.

\section{Materials and Methods}

The study area was a $60 \mathrm{ha}$ dynamics plot in the tropical montane rain forest $\left(18.23^{\circ}-18.50^{\circ} \mathrm{N}, 108.36^{\circ}-\right.$ $109.05^{\circ} \mathrm{E}$ ) with an elevation of $800-1000 \mathrm{~m}$, located in Jianfengling, in the southwest region of Hainan Island, China(Li \& Zhou 2002). The climate of the studied area is tropical and rainy climate, with a mean annual precipitation of $1700-2600 \mathrm{~mm}$, and a mean annual temperature of $20-25^{\circ} \mathrm{C}$ (Yang et al. 2016). The main plant families are Lauraceae, Rubiaceae, Fagaceae, Myrtaceae (Li \& Zhou 2002) and the soil belongs to the Ultisols order according to the USDA Soil Taxonomy.

Based on the technical specifications of the Centre for Tropical Forest Science, Smithsonian Institute, the 60 ha dynamics plot was divided into 1500 quadrants, each $20 \mathrm{~m} \times 20 \mathrm{~m}$ in size. Figure 1 shows the distribution of the 60 randomly selected soil sampling sites from the 1500 quadrats. In each sampling site, the cutting ring method was used to obtain topsoil $(0-10 \mathrm{~cm})$ samples (each sample including four replicates). In total, 240 soil samples were collected and brought back to the laboratory. A part of each soil sample was stored at $4^{\circ} \mathrm{C}$ to measure acid phosphatase activity (APA). A part was air-dried and sieved over $2 \mathrm{~mm}$ to characterize soil particle size (sand, silt and clay content). The 
82 rest of soil sample was air-dried and ground into $1 \mathrm{~mm}$ to analyse soil total nitrogen (TN), total phosphorus (TP),

83

84 available phosphorus (AP), soil $\mathrm{pH}$, and SOC chemical fractions.

Soil samples were pretreated with 10\% (v/v) hydrofluoric acid (HF) solutions before solid-state 13C-CPMAS NMR analysis, to remove $\mathrm{Fe}^{3+}$ and $\mathrm{Mn}^{2+}$ in the soil, improving the signal/noise ratio. In detail, $10 \mathrm{~g}$ ground soil sample was vibrated for 2 hours with $50 \mathrm{ml} \mathrm{HF}$ solutions and then centrifuged $(3,000 \mathrm{rpm})$ for 10 minutes to separate the suspension. The above steps were repeated five times to obtain the precipitate (Mathers et al. 2002). The precipitate was washed 5 times with $50 \mathrm{ml}$ deionized water to remove residual HF, then freeze-dried for further analysis. The fractions of SOC were measured with a 13C CPMAS/NMR, $4 \mathrm{~mm}$ probe pulse sequence. The CPTOSS 13C resonant frequency was $100.38 \mathrm{MHz}$, the $1 \mathrm{H}$ resonant frequency was $399.16 \mathrm{MHz}$, rotation speed was $5 \mathrm{kHz}$, the contact time was $3 \mathrm{~ms}$ and cycle time was $1 \mathrm{~s}$ with a sampling frequency of $4 \mathrm{k}$. According to a previous study (Baldock et al. 1992), different peaks represent different $C$ compounds: $0-45$ ppm is alkyl carbon, $45-110$ ppm is O-alkyl carbon, $110-160 \mathrm{ppm}$ is aromatic carbon, and $160-220 \mathrm{ppm}$ is carbonyl carbon. A total of 240 soil samples were analysed in the Analytical Centre of the Institute of Chemistry Chinese Academy of Sciences (Beijing City). MestRe-C software was used to analyse the chemical fractions of the SOC. We used two indices, the decomposition index (DI) and the inertia index (II), to represent SOC stability.

$$
\begin{aligned}
& D I=\frac{\text { alkyl carbon }}{0-\text { alkyl carbon }} \\
& I I=\frac{\text { alkyl carbon }+ \text { aromatic carbon }}{0-\text { alkyl carbon }+ \text { carboxyl carbon }}
\end{aligned}
$$

The DI can reflect microbial processing with higher ratios indicating losses of more labile $\mathrm{C}$ relative to poorerquality C compounds(Cusack et al. 2011), therefore, the higher ratio, the more stable is the SOC (Chen 2012; Ostertag et al. 2008). Higher II values mean more alkyl carbon and aromatic carbon exists in the SOC, indicating higher SOC stability (Ostertag et al. 2008), which is beneficial for SOC accumulation.

Soil organic carbon and total $\mathrm{N}$ contents were determined by the $\mathrm{K}_{2} \mathrm{Cr}_{2} \mathrm{O}_{7}-\mathrm{H}_{2} \mathrm{SO}_{4}$ oxidation method and the Kjeldahl procedure respectively(Liu et al. 2012). Soil total phosphorus (TP) was extracted by the semimicro kelvin method and measured by an automatic flow analyzer (PROXIMA 1022/1/1, ALLIANCE instruments, France). Soil ammoniacal nitrogen $\left(\mathrm{NH}_{4}{ }^{+}-\mathrm{N}, \mathrm{AN}\right)$ content was extracted using $2 \mathrm{M} \mathrm{KCl}$ on an orbital shaker for $1 \mathrm{~h}$ under ambient temperature and then the suspension was filtered. The extracts were analysed by a continuous flow analytical system (SKALAR San++, SKALAR Co., Netherlands). Soil available phosphorus (AP) was determined by the ammonium chloride-hydrochloric acid extraction method (Bao 2000), and acid phosphatase activity (APA) was determined by the phosphoric acid bisacid colourimetric method (Guan 1986). Soil moisture (SM) was represented as the ratio of dry soil weight to soil water weight after fresh soil samples were dried at $105^{\circ} \mathrm{C}$ for $24 \mathrm{~h}$. Soil $\mathrm{pH}$ was detected by the potentiometric method, where $10 \mathrm{~g}$ air-dried soil was put into a $25 \mathrm{ml}$ beaker and added with distilled water and kept for 30 minutes, after which the suspension's $\mathrm{pH}$ value was measured with a corrected $\mathrm{pH}$ meter. Soil particle size distributions were determined by wet sieving (ChaudhariSingh \& Kundu 2008).To investigate the effects of local topography on soil properties, we binned each data point into a topography type based on elevations, slopes and convexities by fuzzy $C$-mean clustering cluster analysis(Xu et al. 2015). Four topography types were identified: a flat area, a relative steep area, a steep area and a mountaintop area. We then performed one-way ANOVAs to test the differences in the soil properties between the topographic groups. The soil property was regarded as significantly 
119 different if P-value was $\leq 0.05$. All results were shown as mean $\pm \mathrm{SE}$. Path analysis provides a way to examine the 120 multiple relationships between SOC stability and environmental factors. Thus, a path analytic framework was applied 121 to examine the influencing factors on SOC stability across the different topographies. As soil nutrients and other soil 122 properties did not have significant difference among the four topographies. The flat and the top area were classified 123 into the relative flat (RF) areas and the rest two types into the relative steep (RS) areas according to Wang et al. (2018).

124 The RF areas had more favorable nutrients and environment than the RS areas and could be applied to validate the hypothesis we proposed previously.

All analyses were conducted using SPSS Version 20 and figures were generated by Origin (version 92 E).

\section{3. Results}

\subsection{Soil properties of the different topography types}

129 Soil properties varied among the different topographies. To be specific, SOC increased from flat areas to mountaintop 130 areas, with $29.66 \mathrm{~g} / \mathrm{kg}$ in flat areas and $41.97 \mathrm{~g} / \mathrm{kg}$ in mountaintop areas. Soil TN tended to increase in mountaintop 131 areas, with $1.47 \mathrm{~g} / \mathrm{kg}$ in flat areas and $1.78 \mathrm{~g} / \mathrm{kg}$ in mountaintop areas. However, soil C:N ratios were similar across 132 the different topographies. The AN, TP and SM were also the highest in the mountaintop areas, whereas the contents 133 of $\mathrm{pH}$ was highest in the flat areas. Soil particle size did not change with topography except slit content was high in 134 the flat area (Figure 2 and Table 1).

\section{3.2. SOC components of the different topography types}

Alkyl carbon, on average $41.67 \%$ of the SOC, was the largest component of the SOC chemical fractions in the four different topography types (Figure 3). Aromatic carbon, which accounted for only $2.61 \%$, was the lowest SOC component. O-alkyl carbon and carboxyl carbon took up $33.08 \%$ and $22.80 \%$ of the SOC, respectively. As illustrated in Figure 4, the overall distributions of the fractions of the SOC were similar across the different topography types. However, the proportion of alkyl carbon and carboxyl carbon was significantly altered by topography. The alkyl carbon content increased from the flat to mountaintop areas, with $38.87 \%$ in flat areas and $43.34 \%$ in mountaintop areas, while the carboxyl carbon content decreased from $24.78 \%$ in flat areas to $21.24 \%$ in mountaintop areas. O-alkyl carbon and aromatic carbon content did not change differently with topography.

\subsection{SOC stability indices of the different topography types}

In all four topographies, the DI was higher than 1 and the II was higher than 0.7 . The DI was not significantly

146 different among the topographies, while II was significantly different in different topographies with the lowest II value 147 in the flat areas (0.72) and the highest value in the steep areas (0.91) (Figure 5).

\subsection{Influencing factors on SOC stability of the different topography types}

149 Figure 6 shows that the influencing factors and mechanisms of SOC stability were different in the different 150 topography types. In the RF areas, SOC, AN and SM together explained 52\% of the variability in the SOC stability. 
151 SOC and AN directly positively affected SOC stability; high SOC and AN strengthened SOC stability. SM directly

152 negatively influenced SOC stability, however, the direct negative effect of SM was partly offset by the indirect positive

153 effect of SM on AN and SOC, thus, SM had little overall effects on SOC stability. Besides, SOC were positively

154 correlated with soil silt content in this area (Figure 7). However, soil particle size was not adopted by the model.

155 In the RF areas, SM and AN together explained 26\% variability of SOC stability. In the RS areas, SM and AN

156 also affected SOC stability by $42 \%$. The effect was the same as for RF areas, though the effect of SM was larger than

157 that of AN on SOC stability. Increasing SM decreased SOC stability, though this negative effect was partly offset

158 bySM's indirect effect on AN. AN directly positively affected SOC stability.

159 Soil AN and SM were both influencing factors on SOC stability in the RF areas and the RS areas, however, the

160 scale of their effect differed. Specifically, SM was a negligible limiting factor in the RF areas, whereas SM was the

161 most important limiting factor in the RS areas. The path analyses model had an R square of 0.53 in the RF areas, while

162 this was 0.42 in the RS areas (Table S1).

\section{4. Discussion}

164 The chemical fractions of the SOC in the different topographic areas were characterized by alkyl carbon $>$ O165 alkyl carbon $>$ carboxyl carbon $>$ aromatic carbon. The ranking of the SOC fractions is similar to those of subtropical 166 evergreen board-leaved forest and Masson pine in China (Shang et al. 2013), and subtropical natural forest and hoop 167 pine plantation in Australia (ChenXu \& Mathers 2004) with 13CNMR technology. Alkyl carbon was the largest 168 component of the SOC fractions, indicating that the SOC comprised a higher percentage of passive carbon in SOC.

169 The DI (alkyl carbon/O-alkyl carbon) for the 60ha was 1.29, which is higher than moist semi-deciduous tropical forest 170 soils in Ghana (1.25) (ElberlingBreuning-Madsen \& Knicker 2013), Costa Rican old live oak forest (0.87) and old171 growth dry tropical forests (0.70) (LorenzLal \& Jiménez 2010), plantations in the subtropics of China (Pinus 172 massoniana, Castanopsis hystrix, Michelia macclurei, Mytilaria laosensis, all $<0.8$ )(Wang 2010), evergreen broad173 leaved forest (0.76), Cunninghamia lanceolata forest (0.89), Cryptomeria fortune forest (0.78), and coniferous and 174 broad-leaved mixed forest (0.53) in the subtropics of China (Zhang et al. 2015). The DI of all the different topography 175 types was all higher than 1, indicating a rather stable SOC in the tropical montane rainforest of Jiangfengling, Hainan 176 Island(González-Pérez et al. 2008). Studies of changes in SOC and its fractions of forest along a climatci gradient in

177 China found higher mean annual temperature sites would have greater alkyl C proportion and higher DI value as active 178 SOC decomposition processes accelerated(Sun et al. 2019).Path analysis showed that the SOC contents only affected 179 SOC stability in RF areas, while AN and SM affected SOC stability in both topographies. Studies have found that 180 interactions between SOC and mineral surfaces can stabilise SOC, whereby stable organic-mineral bonds were formed 181 through anion and inner-sphere ligand-exchange reaction (Wiesmeier et al. 2019). Tropical forest with highly 182 weathered soils contains high concentrations of iron (Sanchez 1976) that could protect C from microbes and enhance 183 SOC stability. Studies found $\mathrm{Fe}^{3+}$ was positively correlated with the SOC content (Wang et al. 2019). That the SOC 184 only affected SOC stability in the RF areas might be due to the fact that SOC content in the RF areas was significantly 185 higher than that in the RS areas $(37.21>31.32 \mathrm{~g} / \mathrm{kg}, \mathrm{p}<0.01)$. 
SOC stability depends not only on its chemical characteristics, but also on the soil microenvironment (Yang et

187 al. 2020). Soil biotic community and the soil microenvironment are key factors that affecting the SOC stability

188 (Schmidt et al. 2011; Yang et al. 2018). Soil N, especially in the bioavailable forms, such as ammoniacal nitrogen is

189 an essential component of all living organisms. Soil N dynamics are mainly driven by microbes (Levy-BoothPrescott

190 \& Grayston 2014) and microbes mainly assimilate of AN (Cheng et al., 2015), however, some studies have found that

191 nitrogen addition negatively affects soil microbial growth, composition and function(Chen et al. 2018). The soil AN

192 content in the study area was rather high at about $40.4 \mathrm{mg} / \mathrm{kg}$ while the value in Amazon pristine forest was 5.7

$193 \mathrm{mg} / \mathrm{kg}$ (Hamaoui et al. 2016) and the value in a secondary tropical forest in Southern China was $2.12 \mathrm{mg} / \mathrm{kg}$ (Wang et

194 al. 2014). Therefore, microorganism activities and functions might be suppressed by the high AN content in this area,

195 resulting in a slow decomposition rates and consequently high SOC stability in this tropical forest.

196 Soil moisture is a key factor influencing SOC mineralization in terrestrial ecosystems (LiuZhang \& Wan 2009;

197 MoyanoManzoni \& Chenu 2013). Soil moisture can affect SOC decomposition directly or indirectly. Topography

198 influences soils by the transport of fine soil particle towards the base of slopes and lower slope positions in what are

199 called depositional areas, which tend to have high organic materials and water-holding capacity (Chapin IIIMatson \&

200 Vitousek 2012). The above process results in the deposition of more active carbon than passive carbon, explaining the

201 low DI and II in the RF areas. This explains why SM was a negative influencing factor of SOC stability in the RS and

202 RF areas (Figure 6). Moreover, the SOC in the flap areas was the most unstable of all of the four topography types

203 (Figure 4). In terms of indirect effects, decomposition of soil organic matter depends on factors such as soil

204 mineralogy, redox potential and electron acceptor availability, which are controlled by soil water regimes (RoJi \& Lee

205 2018). Studies have found that an increase in soil water content benefits dissolved organic carbon dissolution and

206 nutrients transfer, which stimulate the activity of microorganisms which involved in organic carbon

207 decomposition(Goebel et al. 2007). Higher SM results in higher rates of substate supply to the microbes and, thereby,

208 higher microbial growth. In addition, soil moisture availability can affect the vegetation distribution and structure

209 (D'Odorico et al. 2007; Ruiz-Sinoga et al. 2011), affecting the amount and quality of litter, which in turns influences

210 the soil organic matter_decomposition rate (Rodríguez-Iturbe \& Porporato 2007). On the other hand, AN is water-

211 soluble nitrogen which is vulnerable to the influence of soil water. Hence, SM could negatively affect SOC stability

212 by positively influencing the soil microbe and AN content.

\section{5. Conclusions}

214 Our analysis of the effects of small-scale topography on SOC stability in a tropical mountain rain forest showed

215 that topographic heterogeneity altered SOC stability by changing soil nutrients and soil moisture. Our findings

216 indicated that SOC is rather stable in the tropical montane rainforest topsoil and AN and SM were the main influencing

217 factors of SOC stability both in RF and RS areas. Furthermore, SOC and AN positively promote SOC stability while

218 SM was a limiting factor on SOC stability in this study areas. Accordingly, soil nutrients were the key influencing

219 factors in RF areas but not in RS areas. Our hypothesis that nutrients and soil environment be the key influencing

220 factor in study areas were partly confirmed, considering that the path analysis models explained less than $50 \%$ of the

221 SOC stability in the RS areas, thus other factors remain to be further explored.

Peer] reviewing PDF | (2021:04:60228:2:0:NEW 27 Jul 2021) 


\section{Acknowledgments}

223 We are grateful to Jianfengling National Key Field Research Station for Tropical Forest Ecosystem for providing 224 their assistance in field work.

\section{Conflict of interest}

226 The authors declare no competing financial interests. 
228

229

230

231

232

233

234

235

236

237

238

239

240

241

242

243

244

245

246

247

248

249

250

251

252

253

254

255

256

257

258

259

260

261

262

263

264

\section{References}

Angst G, Mueller KE, Eissenstat DM, Trumbore S, Freeman KH, Hobbie SE, Chorover J, Oleksyn J, Reich PB, and Mueller CW. 2018. Soil organic carbon stability in forests: Distinct effects of tree species identity and traits. Glob Chang Biol 25:1529-1546. 10.1111/gcb.14548

Baldock JA, Oades JM, Waters AG, Peng X, Vassallo AM, and Wilson MA. 1992. Aspects of the chemical structure of soil organic materials as revealed by solid-state 13C NMR spectroscopy. Biogeochemistry 16:1-42.

Bao s. 2000. Soil agrochemical analysis BeiJing: Chinese Agriculture Press.

Chapin III FS, Matson PA, and Vitousek PM. 2012. Principles of terrestrial ecosystem ecology. New York: Springer.

Chaudhari SK, Singh R, and Kundu DK. 2008. Rapid Textural Analysis for Saline and Alkaline Soils with Different Physical and Chemical Properties. Soil Science Society of America Journal 72:431-441. 10.2136/sssaj2006.0117N

Chen CR, Xu ZH, and Mathers NJ. 2004. Soil Carbon Pools in Adjacent Natural and Plantation Forests of Subtropical Australia. Soil Science Society of America Journal 68:282-291. 10.2136/sssaj2004.2820

Chen x. 2012. The effects of major environmental changes on soil organic carbon fractions in subtropical forests Doctor. Chinese Academy of Sciences.

Chen X, Deng Q, Lin G, Lin M, and Wei H. 2018. Changing rainfall frequency affects soil organic carbon concentrations by altering non-labile soil organic carbon concentrations in a tropical monsoon forest. Sci Total Environ 644:762-769. 10.1016/j.scitotenv.2018.07.035

Christensen B. 1996. Carbon in primary and secondary organomineral complexes. In: chapter,Structure and Organic Matter Storage in Agricultural Soils. New York: CRC Lewis Publishers.

Cusack D, Silver W, Torn M, Burton S, and Firestone M. 2011. Changes in microbial community characteristics and soil organic matter with nitrogen additions in two tropical forests. Ecology 92:621-632. 10.1890/10-0459.1

D'Odorico P, Caylor K, Okin GS, and Scanlon TM. 2007. On soil moisture-vegetation feedbacks and their possible effects on the dynamics of dryland ecosystems. Journal of Geophysical Research: Biogeosciences 112:1-10. 10.1029/2006jg000379

Elberling B, Breuning-Madsen H, and Knicker H. 2013. Carbon sequestration in iron-nodules in moist semi-deciduous tropical forest soil. Geoderma 200-201:202-207. 10.1016/j.geoderma.2013.03.001

Fernández-Romero ML, Lozano-García B, and Parras-Alcántara L. 2014. Topography and land use change effects on the soil organic carbon stock of forest soils in Mediterranean natural areas. Agriculture, Ecosystems $\mathcal{E}$ Environment 195:1-9. 10.1016/j.agee.2014.05.015

Fontaine S, Barot S, Barre P, Bdioui N, Mary B, and Rumpel C. 2007. Stability of organic carbon in deep soil layers controlled by fresh carbon supply. Nature 450:277-280. 10.1038/nature06275

Goebel M-O, Woche SK, Bachmann J, Lamparter A, and Fischer WR. 2007. Significance of Wettability-Induced Changes in Microscopic Water Distribution for Soil Organic Matter Decomposition. Soil Science Society of America Journal 71:1593-1599. 10.2136/sssaj2006.0192

González-Pérez M, Vidal Torrado P, Colnago LA, Martin-Neto L, Otero XL, Milori DMBP, and Gomes FH. 2008. 13C NMR and FTIR spectroscopy characterization of humic acids in spodosols under tropical rain forest in southeastern Brazil. Geoderma 146:425-433. 10.1016/j.geoderma.2008.06.018

Peer] reviewing PDF | (2021:04:60228:2:0:NEW 27 Jul 2021) 
265 Guan S. 1986. Soil enzyme and research methods. BeiJing: Chinese Agriculture Press.

266 Hamaoui GS, Rodrigues JLM, Bohannan BJM, Tiedje JM, and Nüsslein K. 2016. Land-use change drives abundance and community structure alterations of thaumarchaeal ammonia oxidizers in tropical rainforest soils in Rondônia, Brazil. Applied Soil Ecology 107:48-56. 10.1016/j.apsoil.2016.05.012

269

270

Hassink J. 1997. The capacity of soils to preserve organic C and N by their association with clay and silt particles. Plant and Soil 191:77-87. 10.1023/A:1004213929699

271

J. Six RTC, E. A. Paul \& K. Paustian. 2002. stabilization mechanisms of soil organic matter implications for c saturation

272 of soil. Plant and Soil 241:155-176.

273

Ktigel-Knabner I. 1997. 13C and 15N NMR spectroscopy as a tool in soil organic matter studies. Geoderma 80:243-270.

274

Levy-Booth DJ, Prescott CE, and Grayston SJ. 2014. Microbial functional genes involved in nitrogen fixation,

275

276

277

278

279 nitrification and denitrification in forest ecosystems. Soil Biology and Biochemistry 75:11-25. 10.1016/j.soilbio.2014.03.021

Li Y, Xu H, Luo T, Chen D, and Lin M. 2012. Permanent monitoring and research dataset of Chinese ecosystem:forest ecosystem. Jianfengling Station.Bio-species checklist. BeiJing: Chinese Agriculture Press.

Li Y, and Zhou G. 2002. Research and conservation of tropical forest and the biodiversity, Hainan Island. BeiJing: Chinese Forestry Press.

281

Liu M, Chen X, Guo J, Li H, and Hu F. 2007. Soil Biota on Soil Organic Carbon Stabilization. Advances in Earth Science 282 22:152-158.

283

Liu W, Chen S, Qin X, Baumann F, Scholten T, Zhou Z, Sun W, Zhang T, Ren J, and Qin D. 2012. Storage, patterns, and

284

285

286

287

288

289

290

291

292

293

294

295

296

297

298 control of soil organic carbon and nitrogen in the northeastern margin of the Qinghai-Tibetan Plateau. Environmental Research Letters 7:035401. 10.1088/1748-9326/7/3/035401

Liu W, Zhang Z, and Wan S. 2009. Predominant role of water in regulating soil and microbial respiration and their responses to climate change in a semiarid grassland. Global Change Biology 15:184-195. 10.1111/j.13652486.2008.01728.x

Lorenz K, Lal R, and Jiménez JJ. 2010. Characterization of soil organic matter and black carbon in dry tropical forests of Costa Rica. Geoderma 158:315-321. 10.1016/j.geoderma.2010.05.011

Mathers NJ, Xu Z, Berners-Price SJ, Perera MCS, and Saffigna PG. 2002. Hydrofluoric acid pre-treatment for improving 13C CPMAS NMR spectral quality of forest soils in south-east Queensland, Australia. Aust J Soil Res 40:655674.

Moyano FE, Manzoni S, and Chenu C. 2013. Responses of soil heterotrophic respiration to moisture availability: An exploration of processes and models. Soil Biology and Biochemistry 59:72-85. 10.1016/j.soilbio.2013.01.002

Ostertag R, Marín-Spiotta E, Silver WL, and Schulten J. 2008. Litterfall and Decomposition in Relation to Soil Carbon Pools Along a Secondary Forest Chronosequence in Puerto Rico. Ecosystems 11:701-714. 10.1007/s10021-0089152-1

299

Pan Y, Birdsey RA, Fang J, Houghton R, Kauppi PE, Kurz WA, Phillips OL, Shvidenko A, Lewis SL, Canadell JG, Ciais P, Jackson RB, Pacala SW, McGuire AD, Piao S, Rautiainen A, Sitch S, and Hayes D. 2011. A large and persistent carbon sink in the world's forests. Science 333:988-993. 10.1126/science.1201609 
302 Ro H-M, Ji Y, and Lee B. 2018. Interactive effect of soil moisture and temperature regimes on the dynamics of soil

$303 \quad$ organic carbon decomposition in a subarctic tundra soil. Geosciences Journal 22:121-130. 10.1007/s12303-017-

$304 \quad 0052-2$

305 Rodríguez-Iturbe I, and Porporato A. 2007. Ecohydrology of Water-controlled Ecosystems: Soil Moisture and Plant Dynamics.

$306 \quad$ United Kingdom: Cambridge University Press.

307 Ruiz-Sinoga JD, Gabarrón Galeote MA, Martinez Murillo JF, and Garcia Marín R. 2011. Vegetation strategies for soil

308 water consumption along a pluviometric gradient in southern Spain. Catena 84:12-20.

309 10.1016/j.catena.2010.08.011

310 Sanchez P. 1976. Properties and management of soils in the tropics. New York: John Wiley and Sons.

311 Schmidt MW, Torn MS, Abiven S, Dittmar T, Guggenberger G, Janssens IA, Kleber M, Kogel-Knabner I, Lehmann J,

312 Manning DA, Nannipieri P, Rasse DP, Weiner S, and Trumbore SE. 2011. Persistence of soil organic matter as

313 an ecosystem property. Nature 478:49-56. 10.1038/nature10386

314 Shang S, Jiang P, Song Z, Li Y, and Lin L. 2013. Composition and stability of organic carbon in the top soil under

315 different forest types in subtropical China. Acta Ecologica Sinica 33:0416-0424.

316 Shi L. 2012. Study on the spatial heterogeneity of soil physical and chemical properties of primary tropical montane 317 rainforest Master. Chinese Academy of Forestry.

318 Six J, Conant RT, Paul EA, and Paustian K. 2002. Stabilization mechanisms of soil organic matter: Implications for C-

319 saturation of soils. Plant and Soil 241:155-176. 10.1023/A:1016125726789

320 Stockmann U, Adams MA, Crawford JW, Field DJ, Henakaarchchi N, Jenkins M, Minasny B, McBratney AB, Courcelles

321 VdRd, Singh K, Wheeler I, Abbott L, Angers DA, Baldock J, Bird M, Brookes PC, Chenu C, Jastrow JD, Lal R,

322 Lehmann J, O’Donnell AG, Parton WJ, Whitehead D, and Zimmermann M. 2013. The knowns, known

323

324

325

326

327

328

329

330

331

332

333

334

335

336

337 unknowns and unknowns of sequestration of soil organic carbon. Agriculture, Ecosystems E Environment 164:80-99. 10.1016/j.agee.2012.10.001

Sun W, Zhu H, and Guo S. 2015. Soil organic carbon as a function of land use and topography on the Loess Plateau of China. Ecological Engineering 83:249-257. 10.1016/j.ecoleng.2015.06.030

Sun X, Tang Z, Ryan MG, You Y, and Sun OJ. 2019. Changes in soil organic carbon contents and fractionations of forests along a climatic gradient in China. Forest Ecosystems 6:1. 10.1186/s40663-019-0161-7

Tsui C-C, Chen Z-S, and Hsieh C-F. 2004. Relationships between soil properties and slope position in a lowland rain forest of southern Taiwan. Geoderma 123:131-142. 10.1016/j.geoderma.2004.01.031

Wang F, Li J, Wang X, Zhang W, Zou B, Neher DA, and Li Z. 2014. Nitrogen and phosphorus addition impact soil $\mathrm{N}(2) \mathrm{O}$ emission in a secondary tropical forest of South China. Sci Rep 4:5615. 10.1038/srep05615

Wang H. 2010. Soil carbon sequestration and the related processes in four subtropical plantations in southern China Doctor. Chinese Academy of Forestry.

Wang J, Han X, Yide L, Mingxian L, Zhang Z, Tushou L, and Dexiang C. 2018. Effects of Topographic Heterogeneity on Community Structure and Diversity of Woody Plants in Jianfengling Tropical Montane Rainforest. Scientia Silvae Sinicae 54:1-11.

338

Wang P, Wang J, Zhang H, Dong Y, and Zhang Y. 2019. The role of iron oxides in the preservation of soil organic matter 339 under long-term fertilization. Journal of Soils and Sediments 19:588-598. 10.1007/s11368-018-2085-1

PeerJ reviewing PDF | (2021:04:60228:2:0:NEW 27 Jul 2021) 
340 Wiesmeier M, Schad P, von Lützow M, Poeplau C, Spörlein P, Geuß U, Hangen E, Reischl A, Schilling B, and Kögel341 Knabner I. 2014. Quantification of functional soil organic carbon pools for major soil units and land uses in 342 southeast Germany (Bavaria). Agriculture, Ecosystems E Environment 185:208-220. 10.1016/j.agee.2013.12.028

343 Wiesmeier M, Urbanski L, Hobley E, Lang B, von Lützow M, Marin-Spiotta E, van Wesemael B, Rabot E, Ließ M,

344 Garcia-Franco N, Wollschläger U, Vogel H-J, and Kögel-Knabner I. 2019. Soil organic carbon storage as a key 345 function of soils - A review of drivers and indicators at various scales. Geoderma 333:149-162. $346 \quad 10.1016 /$ j.geoderma.2018.07.026

347 Xu H, Li Y, Lin M, Wu J, Luo T, Zhou Z, Chen D, Yang H, Li G, and Liu S. 2015. Community characteristics of a 60 ha 348 dynamics plot in the tropical montane rain forest in Jianfengling, Hainan Island. Biodiversity Science 23:192349 201. 10.17520/biods.2014157

350 Yang H, Li Y, Ren H, Luo T, Chen R, Liu W, Chen D, Cu H, Zhou Z, Lin M, Yang Q, Yao H, and Zhou G. 2016. Soil $351 \quad$ organic carbon density and influencing factors in tropical virgin forests of Hainan Island, China. Chinese Journal of Plant Ecology 40:292-303. 10.17521/cjpe.2015.0314

Yang J, Li A, Yang Y, Li G, and Zhang F. 2020. Soil organic carbon stability under natural and anthropogenic-induced perturbations. Earth-Science Reviews 205:103199. 10.1016/j.earscirev.2020.103199

Yang J, Li G, Qian Y, Yang Y, and Zhang F. 2018. Microbial functional gene patterns related to soil greenhouse gas emissions in oil contaminated areas. Sci Total Environ 628-629:94-102. 10.1016/j.scitotenv.2018.02.007

Zhang Y, Hu H, Huang Y, and li T. 2015. Effects of different vegetation restoration models on molecular structure and stability of soil organic carbon. Research of Environmental Sciences 28:1870-1878.

360

Zhu H, Wu J, Guo S, Huang D, Zhu Q, Ge T, and Lei T. 2014. Land use and topographic position control soil organic C and $\mathrm{N}$ accumulation in eroded hilly watershed of the Loess Plateau. Catena 120:64-72. 10.1016/j.catena.2014.04.007 
Figure 1

Distribution of soil sampling sites in the 60ha plot in tropical forests

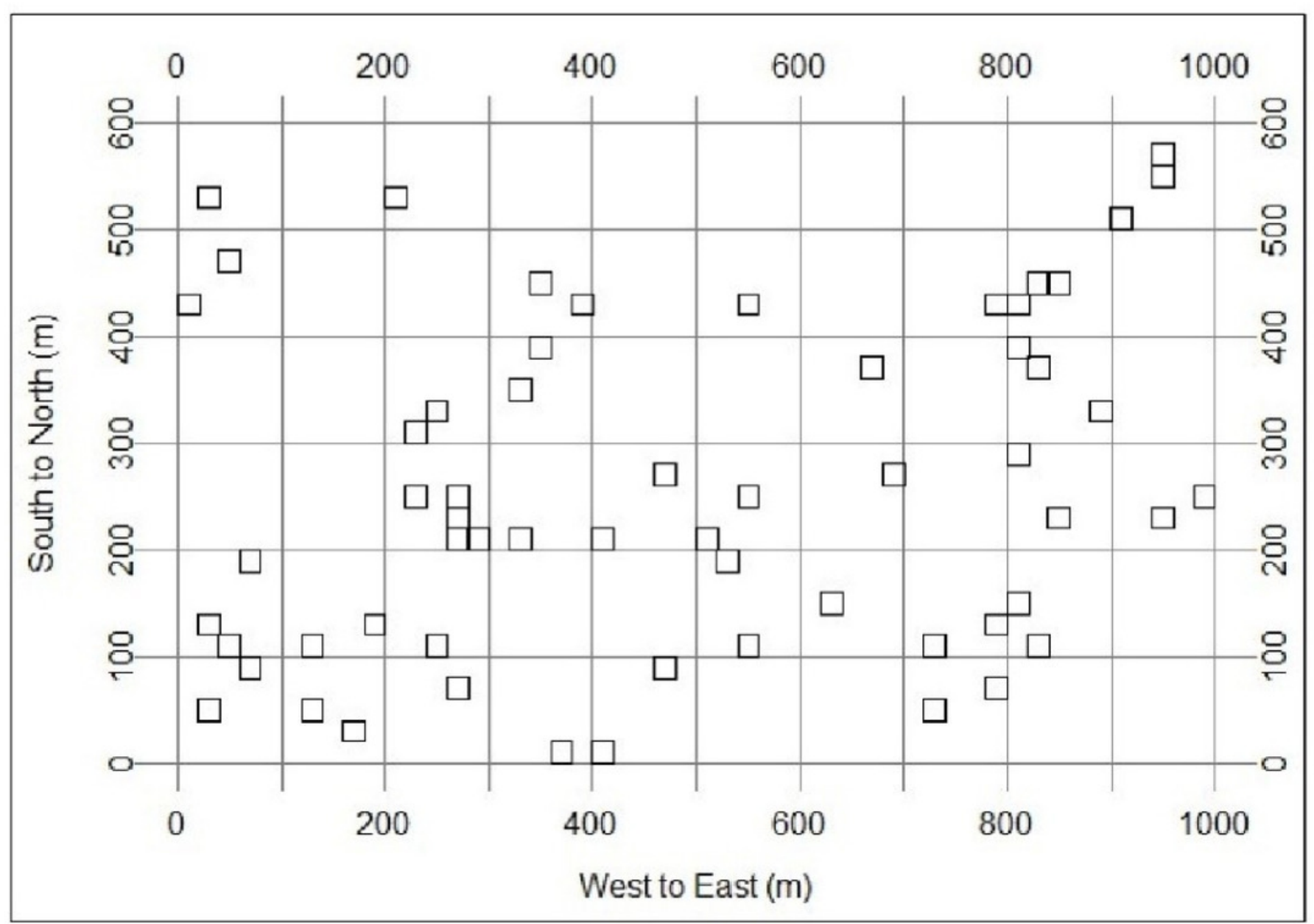


Figure 2

The changes of soil SOC (a), TN (b) and C:N ratio (c) among four topographies. The different lowercases mean significant differences among topographies $(P<0.05)$

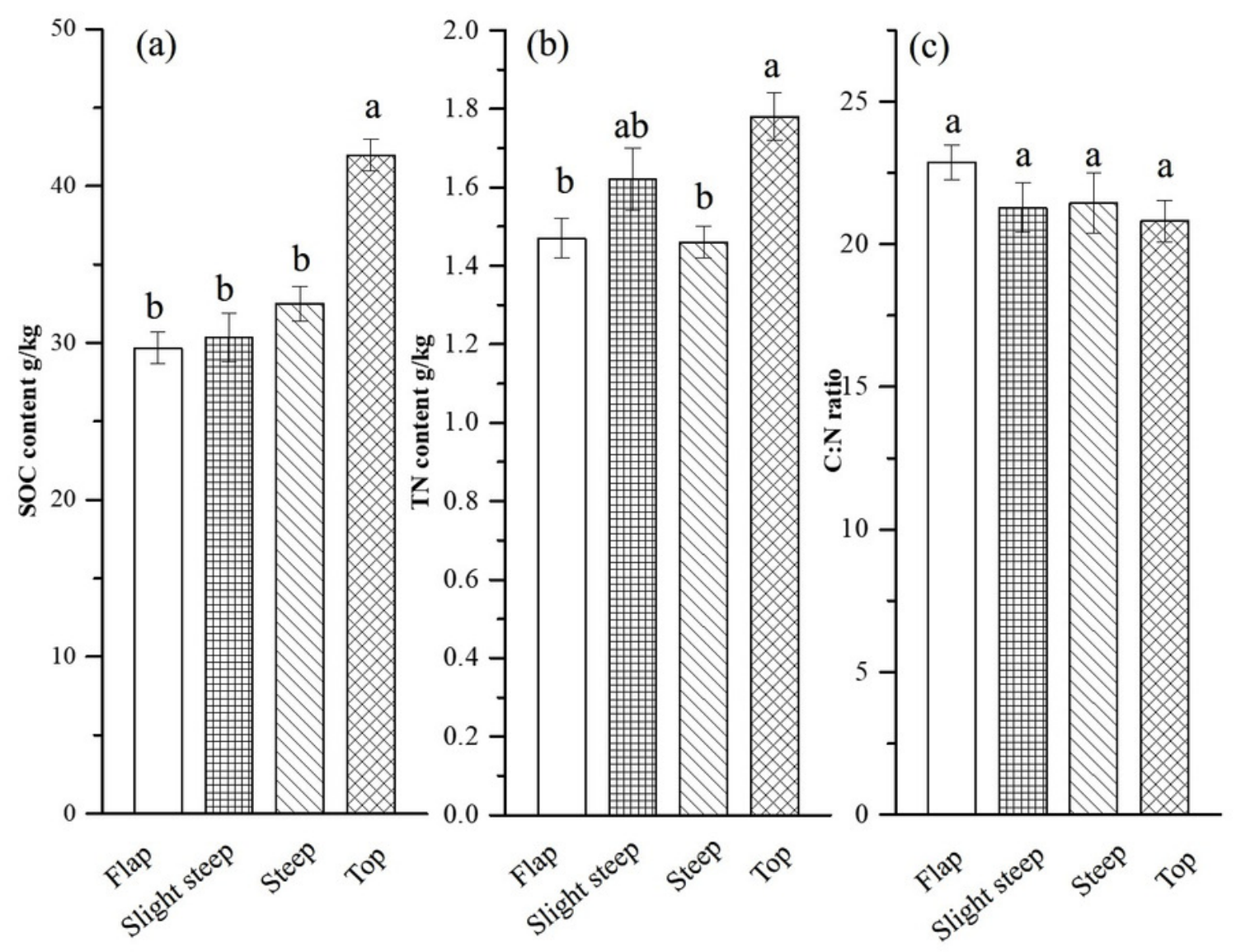


Figure 3

The distributions of $\mathrm{SOC}$ components in this tropical rainforest. Errors Bars represent the standard error (SE)

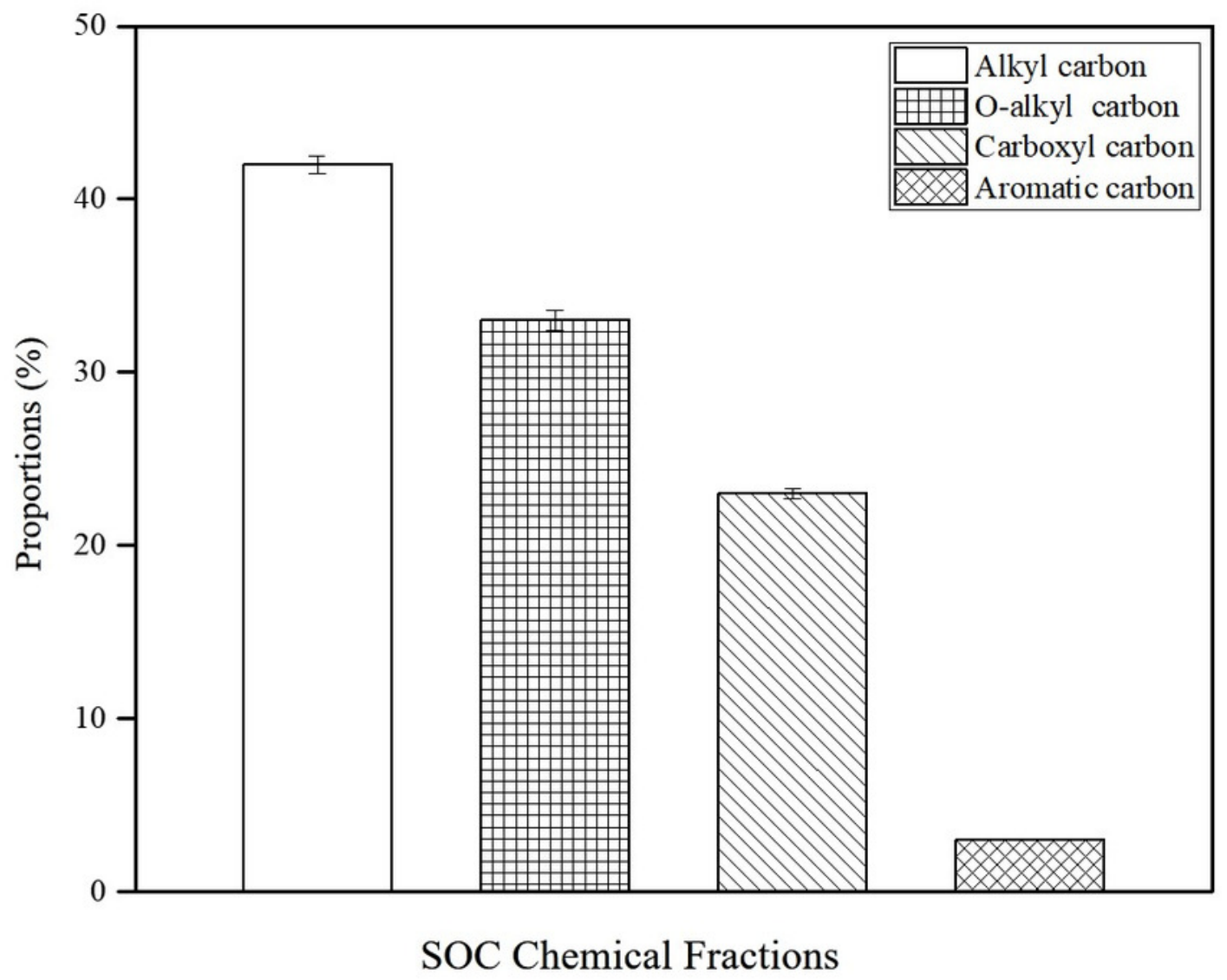


Figure 4

The comparisons of SOC fractions in the four topography types. (a) alkyl carbon, (b)Oalkyl carbon, (c) carboxyl carbon, and (d) aromatic carbon. Errors Bars represent the standard error. The different lowercases mean significant differences among topogra
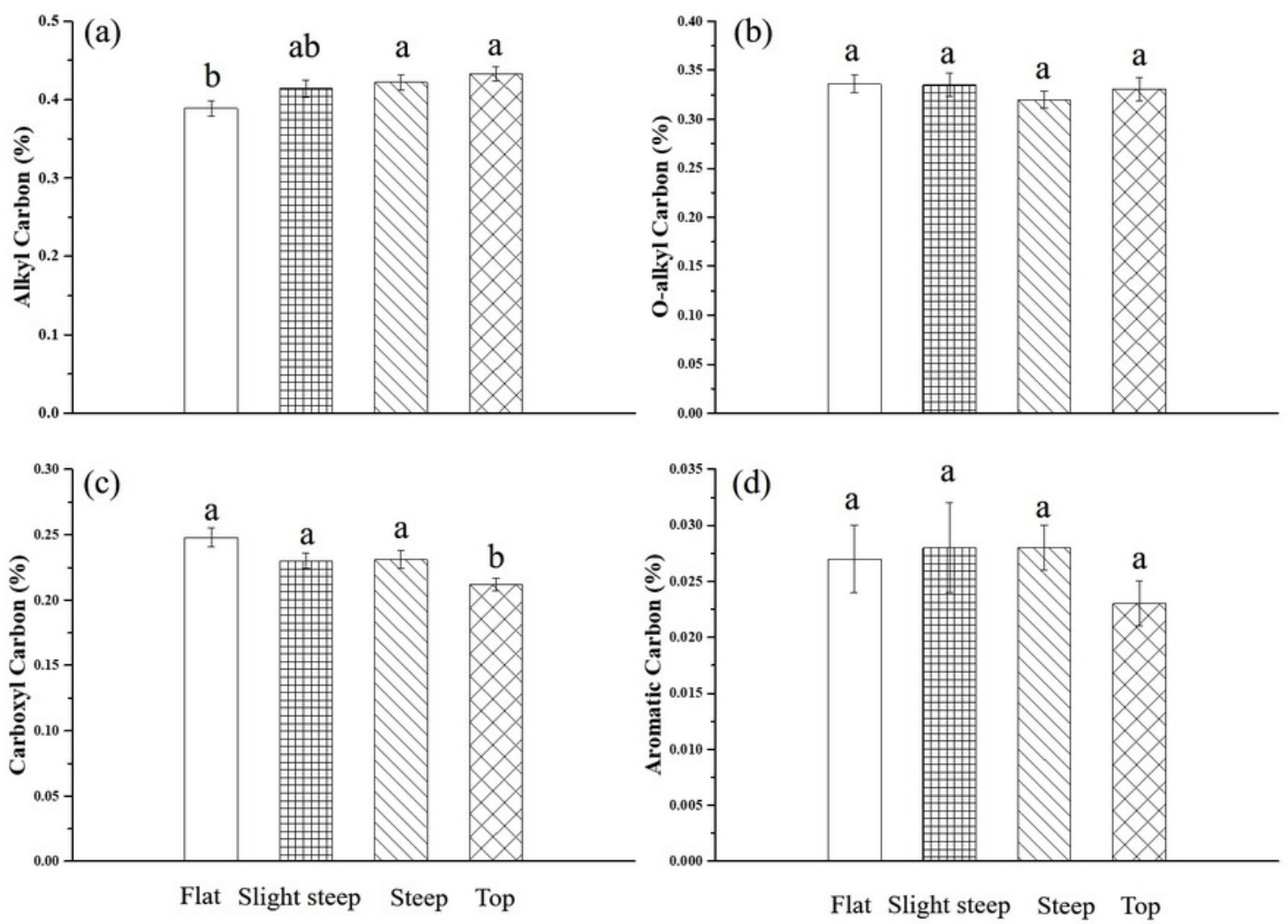
Figure 5

Difference of decomposition index (DI) and inertia index (II) among topographies. (a) decomposition index, (b) inertia index. Errors Bars represent the standard error. The same letter means variables in the different topography types are not significantly

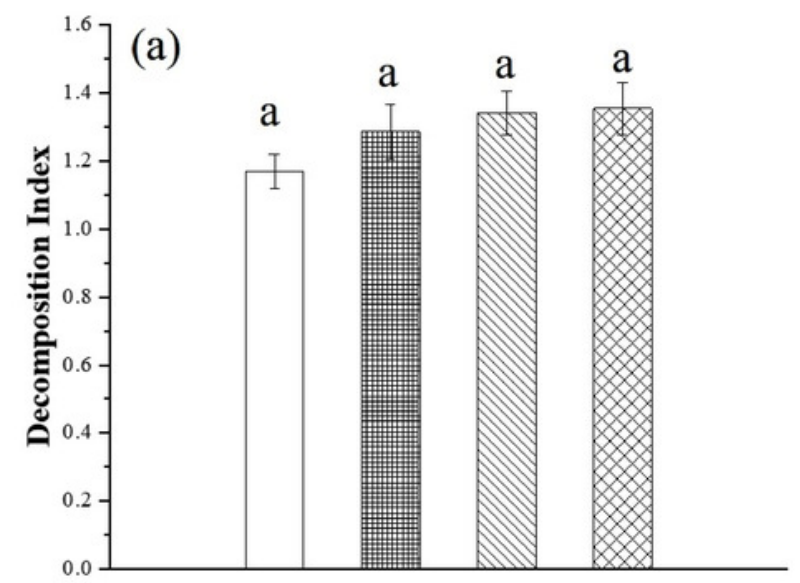

Flat Slight steep Steep Top

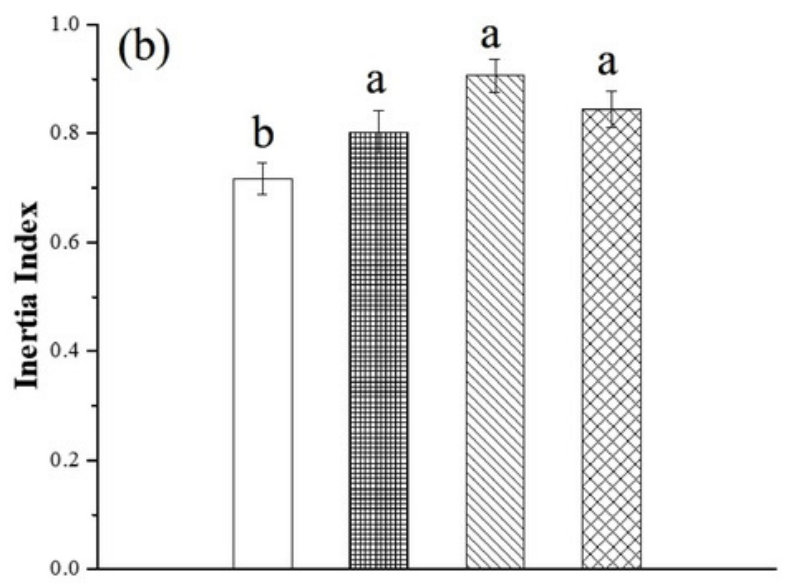

Flat Slight steep Steep Top 
Figure 6

Influencing factors and mechanisms of SOC stability in two topographies. Values aside the straight line are direct path coefficient, and values aside the curve are indirect path coefficient. The direction of arrow is the effect direction.

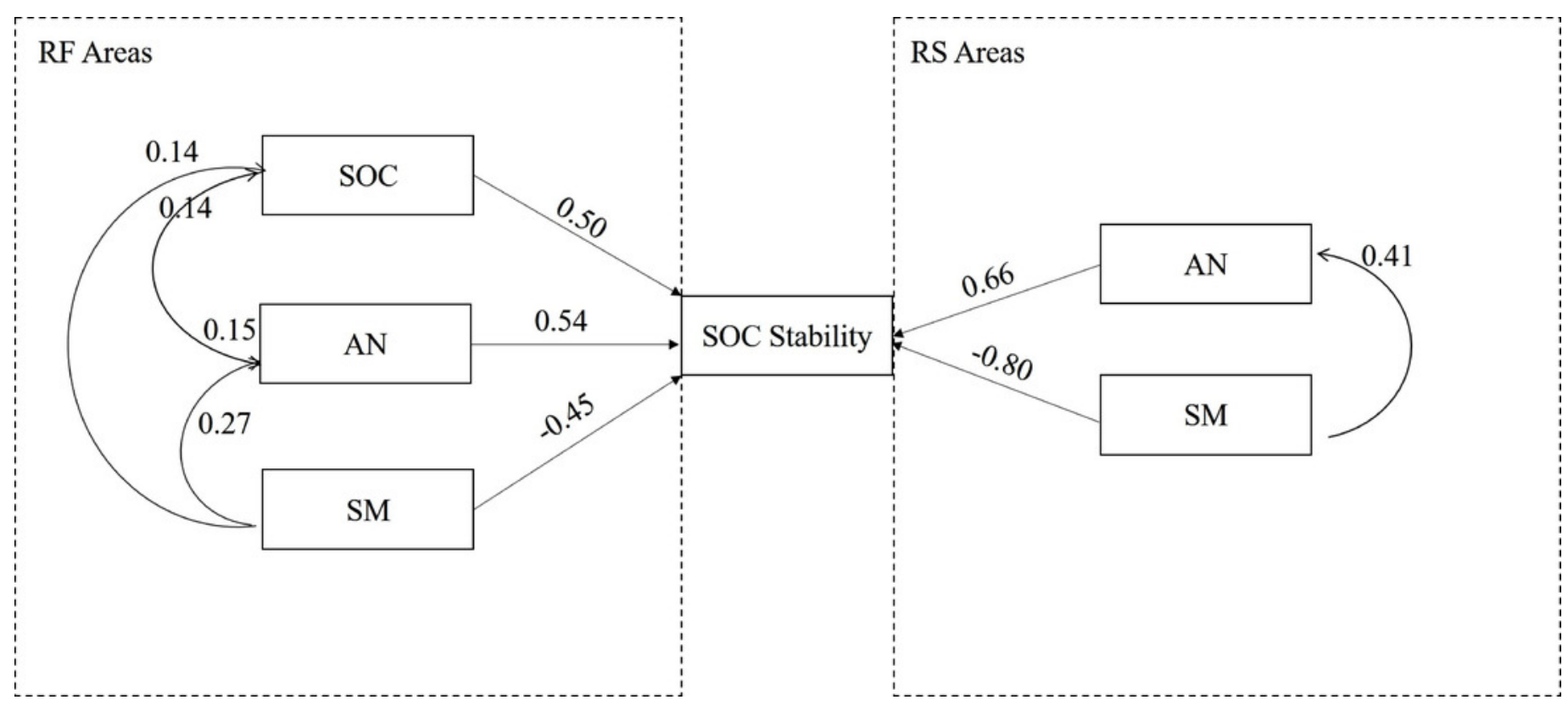


Figure 7

The simple liner relationship between soil texture and SOC content in the relative flat areas 


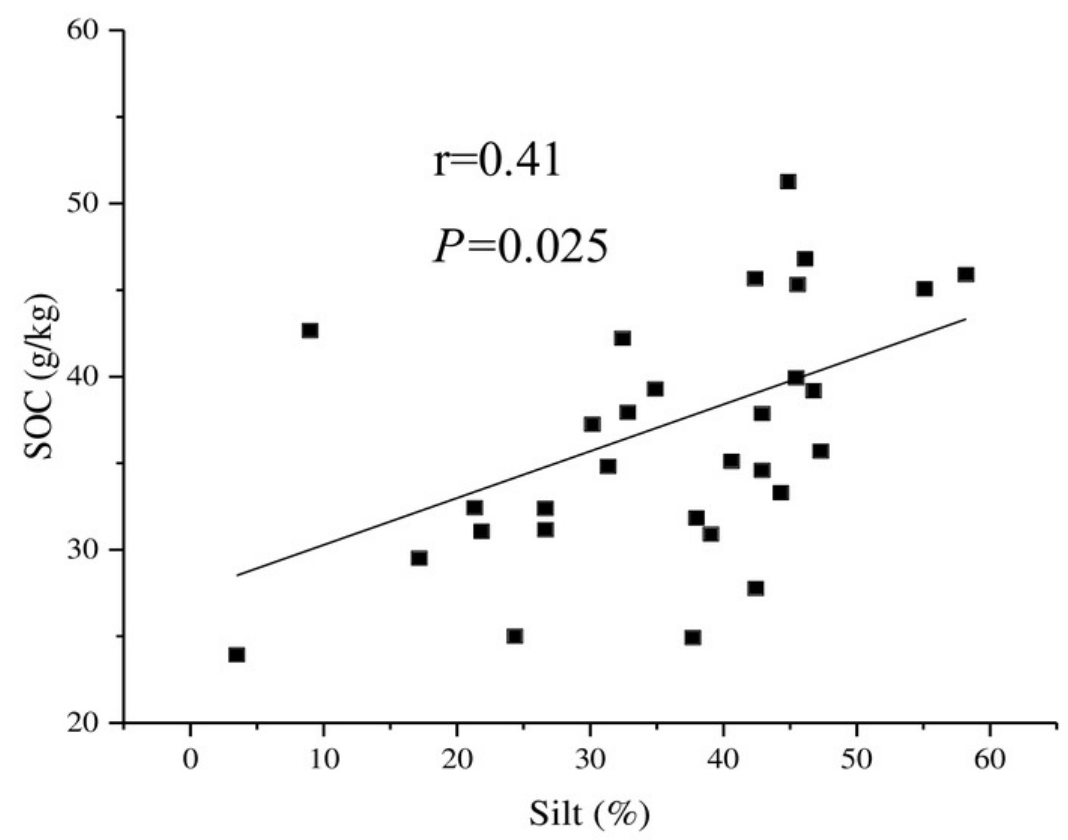




\section{Table 1 (on next page)}

Soil properties in different topographic areas $(n=60)$ 
2

Table 1. Soil properties in different topographic areas $(n=60)$

\begin{tabular}{cccccc}
\hline Variables & $\begin{array}{c}\text { Flat } \\
(\mathrm{n}=12)\end{array}$ & $\begin{array}{r}\text { Slight steep } \\
(\mathrm{n}=16)\end{array}$ & $\begin{array}{c}\text { Steep } \\
(\mathrm{n}=13)\end{array}$ & $\begin{array}{c}\text { Top } \\
(\mathrm{n}=19)\end{array}$ & $\begin{array}{c}\text { Average } \\
(\mathrm{n}=60)\end{array}$ \\
\hline AN $(\mathrm{mg} / \mathrm{kg})$ & $30.29 \pm 6.04 \mathrm{bc}$ & $42.16 \pm 4.32 \mathrm{ab}$ & $29.21 \pm 5.69 \mathrm{c}$ & $53.03 \pm 3.41 \mathrm{a}$ & $40.40 \pm 2.62$ \\
TP $(\mathrm{mg} / \mathrm{kg})$ & $74.12 \pm 5.64 \mathrm{~b}$ & $82.50 \pm 5.62 \mathrm{ab}$ & $77.66 \pm 5.07 \mathrm{~b}$ & $90.91 \pm 3.68 \mathrm{a}$ & $82.40 \pm 2.54$ \\
AP (mg/kg) & $2.71 \pm 0.18 \mathrm{a}$ & $3.03 \pm 0.10 \mathrm{a}$ & $2.92 \pm 0.08 \mathrm{a}$ & $2.30 \pm 0.11 \mathrm{a}$ & $2.93 \pm 0.06$ \\
C:P ratio & $468.65 \pm 34.09 \mathrm{a}$ & $433.61 \pm 25.56 \mathrm{a}$ & $442.74 \pm 43.57 \mathrm{a}$ & $407.08 \pm 24.19 \mathrm{a}$ & $434.20 \pm 15.36$ \\
N:P ratio & $20.56 \pm 1.42 \mathrm{a}$ & $20.26 \pm 0.66 \mathrm{a}$ & $20.39 \pm 1.46 \mathrm{a}$ & $19.68 \pm 0.96 \mathrm{a}$ & $20.16 \pm 0.54$ \\
SM & $20.88 \pm 1.66 \mathrm{cb}$ & $21.20 \pm 1.52 \mathrm{~b}$ & $16.86 \pm 0.83 \mathrm{dc}$ & $25.28 \pm 1.22 \mathrm{a}$ & $21.49 \pm 0.77$ \\
pH & $4.42 \pm 0.05 \mathrm{a}$ & $4.32 \pm 0.05 \mathrm{~b}$ & $4.31 \pm 0.04 \mathrm{ab}$ & $4.15 \pm 0.02 \mathrm{c}$ & $4.28 \pm 0.02$ \\
Sand (\%) & $45.90 \pm 4.81 \mathrm{a}$ & $46.13 \pm 3.28 \mathrm{a}$ & $47.23 \pm 2.72 \mathrm{a}$ & $40.08 \pm 2.20 \mathrm{a}$ & $44.10 \pm 1.61$ \\
Silt (\%) & $27.42 \pm 3.57 \mathrm{~b}$ & $33.60 \pm 2.22 \mathrm{a}$ & $32.61 \pm 2.85 \mathrm{a}$ & $40.24 \pm 2.51 \mathrm{a}$ & $34.53 \pm 1.51$ \\
Clay (\%) & $26.68 \pm 6.58 \mathrm{a}$ & $20.27 \pm 4.14 \mathrm{a}$ & $20.16 \pm 4.13 \mathrm{a}$ & $19.68 \pm 3.18 \mathrm{a}$ & $21.37 \pm 2.17$ \\
\hline
\end{tabular}

4 Abbreviation: AN was ammoniacal nitrogen; TP was total phosphorus; AP was available 5 phosphorus; C:P ratio was calculated as SOC/ TP; N:P ratio was calculated as TN/TP; SM was 6 soil moisture, and $\mathrm{n}$ was sample size. All values were expressed as mean values $\pm \mathrm{SE}$. The different 7 lowercases mean significant differences among topographies $(\mathrm{P}<0.05)$. 